\title{
The Development of Teacher Education for Teachers of the Visually Impaired Learners in Kenya: A Historical Perspective
}

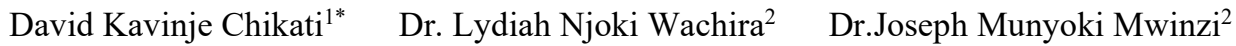 \\ 1.Department of Educational Foundations, University of Nairobi/ Taita Taveta University, Kenya \\ 2.Department of Educational Foundations, University of Nairobi, Kenya
}

\begin{abstract}
History informs the present and helps in prediction of the future. This paper examines the historical development of teacher education for the teachers of the Visually Impaired (VI) learners in Kenya. The paper presents the strides made and the challenges experienced in the development of this type of education from the time it was introduced in Kenya up to the present. Historical research design was employed in data collection, analysis and interpretation. Data was evaluated through external and internal criticisms. The historical inquiry was done through collection of archival data through archival research, collection of data through interviews and research into secondary materials in libraries. Data collected was analyzed qualitatively through triangulation and deduction of themes. The research findings in the paper provide an overview of the state of teacher education for the teachers of the VI in Kenya. The research findings reveal the disintegrated efforts in training of teachers for the VI before the establishment of the first teacher training college for Special Needs Education (SNE) teachers in 1986. The paper presents the developments realized thereafter such as the establishment of SNE departments in some Kenyan Universities.
\end{abstract}

Keywords: Teacher Education, Special Education, Education for Visually Impaired Learners

DOI: $10.7176 / \mathrm{JEP} / 10-32-12$

Publication date: November $30^{\text {th }} 2019$

\section{Introduction}

Education has been and still remains a basic right and a tool to develop the potential of individuals in society regardless of their physical or sensory conditions. In Kenya, education is expressed as a right in Article 53(b) of the Kenyan Constitution of 2010. Article 54 of the Kenyan constitution further extends this right to persons with disabilities by stating that persons with disabilities have a right to access education that is compatible with their interests and needs (GOK, 2010). However, for any system of education to be affective and of reasonable quality, there must be trained and qualified teaching force. Trained and qualified teachers are even more essential when it comes to training of learners with special needs such as the Visually Impaired (VI) (Munyi, 2017). In Kenya, there has been inadequate trained teaching force to handle the VI learners over time (National Gender and Equality Commission [NGEC], 2016). A survey carried out by the National Gender and Equality Commission in 2016 indicated that whereas the Kenyan government has provided education for children with disabilities, special education is had been faced with the challenge of inadequate teachers with the right skills to teach children with disabilities such as the VI learners (NGEC, 2016).

Education for the VI was the first form of Special Education that was introduced in Kenya in the year 1946 through the establishment of Thika Institute for the Blind (Chikati, Wachira \& Mwinzi, 2019). This kind of education was however introduced at the time when there was no any training college for teachers of the VI not only in Kenya but in the entire Africa as well (Ojwando, 1990). Education for the VI in Kenya however grew with time leading to the conversion of Thika Institute for the Blind to a primary school with the name Thika School for the Blind in 1954 (Chikati, Wachira \& Mwinzi, 2019). Other Schools for the VI could later emerge such as St. Lucy's School for the Blind 1958, St. Oda School for the blind in 1961, Likoni School for the Blind in 1965, Kibos School for the Blind in 1965 and St. Francis School for the Blind in 1979.

In 1967, the first special secondary school for the blind in Kenya was established at Thika School for the Blind. Other special secondary schools and units in mainstream secondary schools could later emerge especially after the year 2003 following the adoption of Persons with Disabilities Act. These include St. Lucy's Secondary School for the Blind that was established in the year 2005, St. Francis Secondary School for the Blind established in 2007, Kibos Secondary school for the Blind established in 2009 and Nico Hausa Secondary School for the Blind established at St. Oda School for the Blind in 2013 (MoEST, 2016).

Besides growth in primary and secondary school education for the VI, there have also been some developments in provision of tertiary education to the VI in Kenya. Among the tertiary institutions that have been established overtime include a Farm training center at Kolanya in Western part of Kenya which was established in the year 1956. Others are Chuka farm training center established in 1958, Machakos Institute for the Blind established in 1958 and Sikri Institute for the Blind that was established in 1970 in Nyanza region of Kenya.

Despite these highlighted growth in the number of special education institutions for the VI, there was a 
conspicuous absence of a teacher training college for teachers who could handle the VI learners in these institutions. This could imply that most of the teachers or instructors that taught in these institutions lacked specialized skills of handling the VI learners leading to poor quality in the nature of education that was provided. It was in these regard that this study focused on documenting the historical journey of teacher training programs for teachers of the VI.

\section{Methodology}

The study is a qualitative research that employed the historical research design. This involved systematic location, collection, evaluation and synthesis of evidence in order to establish facts and draw conclusions concerning the development of teacher education for teachers of the VI. This study utilized both primary and secondary sources of data. Primary sources included archival data and oral evidence from informants. Archival data search included analysis of reports as well as original documents such as educational reports and minutes as well as records from special schools for the VI. To ensure reliability of the data collected, the researchers carried out a dual process of establishing the authenticity (external criticism) of the sources and validity of their contents (internal criticism). This was further enhanced by use of triangulation. After the collection of data, the data was verified and validated before being used as historical evidence for the study. The evidence was then analyzed qualitatively. The developments in teacher education for the teachers of the VI as acquired from documentary sources and oral interviews were analyzed qualitatively through triangulation and emerging themes deduced.

\section{Teacher Education for Teachers of the VI in Kenya before Independence}

While efforts were made in establishing schools for the VI in Kenya and Africa at large from the 1940s, there were no schools to train teachers who could handle the visually impaired learners some of whom were totally blind. At the establishment of Thika Institute for the Blind in 1946, there were neither trained teachers to handle the VI learners nor any formally established institution for training of teachers for the visually impaired in Kenya. The only trained person at the institute was therefore the superintendent, Senior-Major Edward Osborne, who had studied various phases of work among the blind in England (KNA, AB/14/34). The teachers and trade instructors at the institute thus started receiving on-the-job training from Major Osborne on how to teach the blind.

The training work of Major Osborne received a boost in 1950 when the Institute received more European workers, some of whom had some knowledge in training of the blind (KNA, AB/14/34). Together with the trained European workers and local teachers who had already been trained, Major Osborne extended the teacher training program at TSB to other persons who were not serving teachers at the Thika Institute for the Blind. This extension commenced in 1954 when the Provincial Commissioner (PC) of Nyanza sent some of the community development assistants to learn about training of the blind at Thika Institute for the Blind. This decision influenced all other PCs who also sent community development assistants for the training (KNA, KTI/3/7/11). The training of community development assistants at the Institute was necessitated by large numbers of blind people in the colony all of whom could not be enrolled at the Thika institute. On return to their regions, these community development assistants were expected to offer training to the blind persons in useful occupations (KNA, KTI/3/7/11).

Thika Institute for the Blind can therefore be cited as being among the first institutions in Africa to offer teacher training programs for teachers of the blind because by 1954, there was no other teacher training college for the blind in Kenya and even in the entire Africa. It was not until 1956 that the first teacher training facility for the VI in Africa, Montfort College was established in Malawi (Ojwando, 1990). The college thus started serving other African countries such as Botswana, Lesotho, Nigeria, Swaziland and Zimbabwe.

In 1956, there was discontent among the teachers of the blind at Thika School for the Blind (TSB) owing to the difference in pay that they were receiving in comparison to teachers in other non-special schools. In an effort to counteract this discontentment, the School Management Committee (SMC) made a recommendation to the government to have more teachers who could teach the blind. The government adopted this recommendation and this led to establishment of a program at TSB that aimed at offering SNE skills to teachers who had trained to handle regular education (KNA, BY/12/21). The SNE skills provided involved training in Braille and mobility guidance which are pertinent aspects to teaching of the VI. A one year conversion course for qualified teachers of ordinary schools was therefore introduced at TSB with the intention of meeting the future needs of the institute for capable teachers. The non-special school teachers were to obtain a certificate that showed their qualification to handle the VI learners as an additional training before they could be allowed to teach. The certificate was referred to as the Blind Certificate.

By October 1956, there were eight teacher trainees at TSB for the conversion course. The school therefore adopted a proposal to build a dormitory for trainees on conversion course thus expanding the capacity for their admission (KNA, BY/12/21). TSB therefore formally established a teacher training center in the school with two categories of trainees: Those trained from teacher training colleges for ordinary schools and those who had not 
received any kind of teacher training but were teaching at TSB. Qualified teachers who obtained a Blind Certificate after conversion course were therefore to work alongside teachers who had only received blind school training from the TSB. A proposal was however put forth in the SMC meeting of $10^{\text {th }}$ October, 1956 for the education department to recognize teachers who had only trained to handle the blind as qualified for employment. The representatives of the education department in the SMC meeting accepted the proposal (KNA, BY/12/21). Teachers trained only at TSB were therefore recognized by the education department as teachers of the blind and were to receive a salary comparable to one that was paid to teachers from training colleges that were also teaching the VI. However the certificates were to be in no way interchangeable and those holding only Teacher of the Blind Certificates could not be employed in non-blind schools.

Thika School for the Blind also collaborated with the neighboring Kilimambogo Teacher Training College in Thika by sending the teacher-trainees who had not received any training before to the college to attend certain general lectures each week in order to improve their competency (KNA, BY/12/21). Kilimambogo Teacher Training College in Thika was for teachers of ordinary schools. The two categories of teachers from TSB went a long way in providing the required manpower not only to TSB but to other schools for the VI that emerged later on from the late 1950s to 1960s such as St. Lucy school for the Blind, St. Oda School for the Blind, Likoni School for the Blind, Kibos School for the Blind and Thika High School for the Blind.

The teachers who obtained the on-job-training at the school were awarded with certificates by the Salvation Army after a considerable time of training and serving. This was determined by the European trainers, who had to be convinced by the teacher's competence in Braille knowledge before such certification. Such teachers were recognized and employed under the Ministry of Education from 1956. Upon the establishment of the Teachers Service Commission in the year 1967, such teachers were recommended by their European trainers for registration and subsequent employment by the commission (KNA, BY/12/21). These teachers remained in the teaching force as qualified teachers for the VI.

When Major Osborne was transferred from the TSB in 1957, his position was taken over by Colonel Swansubarry from England. Along with him, the school also received a few other Europeans who had some knowledge in training of the Blind. With his background in educating the blind, Colonel Swansubarry followed suit of his predecessor by serving as the superintendent as well as a trainer of those teachers who were serving in the school particularly in the area of Braille knowledge (Ojwando, 1990). Together with other Europeans in the institute who had Braille knowledge, Colonel Swansubarry continued with the teacher training program at TSB with emphasis in the area of communication and writing for the blind.

\section{Teacher Education for Teachers of the VI in Kenya after Independence}

After Kenya's independence in 1963, there were disintegrated efforts towards training of teachers besides the training that was being offered at TSB. These included bringing of experts in education for the blind to Kenya by the Royal Commonwealth society for the Blind. The experts provided rigorous short-term in-service courses to teachers of the VI. These were one month courses, spread over a period of six months. However, as one of the former teachers who wished to remain anonymous indicates, the program was very rudimentary and left little impact on the teachers that attended them, apart from the award of certificates of attendance. The program however remains an effort towards improving the competency of the teachers of the VI in Kenya.

The other effort towards training of teachers for the VI came from Christoffel Blinden Mission (CBM) of Germany which in 1978, raised concerns regarding the promotion of teachers of the blind in the country. This came as a result of teachers for the blind remaining in the same salary scale for a long period while their counterparts in regular schools received promotions and salary increments (TSB, P/2/1978). The reason to this discrimination was the view that the teachers of the blind were not as qualified as those in regular schools since most of them had received their training while in service. Consequently, a teacher training program for teachers of the visually handicapped was introduced at Highridge Teachers' College in 1980 under the financial auspices of the CBM. It should be noted that Highridge Teachers' College already existed as a college for ordinary teacher training. The special training course for teachers of the visually handicapped therefore went side by side with the already existing ordinary training at the college. By 1986, the program had led to the award of 51 certificates for teachers of the VI (TSB, P/3/1997).

In 1980, a meeting of special education officials was convened by the head of special education at the ministry of education headquarters for the purpose of formulating a policy guideline that would in future determine the direction of special education in the country. This meeting recommended that an institute be established to train teachers for different disability groups in Kenya. Six years later, this recommendation was adopted resulting into the establishment of Kenya Institute of Special Education (KISE) in 1986. The institute was established through the sponsorship of the Danish International Development Agency (DANIDA). Upon the establishment of KISE all the teacher training programs at TSB and Highridge Teachers' College were terminated and moved to KISE.

Since its establishment, KISE has played a significant role in building the capacity of teachers of the VI 
learners besides other categories of special needs education. This has been achieved through teacher training, teacher in-servicing and research. A survey conducted by the KISE in 1989 revealed that up to $50 \%$ of teachers working with students with disabilities were untrained in the field (KISE/1). The institute therefore strived to fill this gap by providing training of teachers in four categories of special education that includes hearing, visual, physical and intellectual impairment.

The course at KISE involves training of qualified teachers from the existing teacher training colleges or universities. Teachers trained for regular education from other institutions undertake SNE training at KISE leading to diploma or certificate qualifications. The Diploma course runs for two years on a full-time residential basis and three years through distance learning. The certificate course runs as a three month residential in-service course and one year for distance learning (KISE/1).

Presently, teachers posted to schools for the VI in Kenya are those who have received additional training to handle the VI from KISE besides their ordinary teacher training. Besides KISE, Degree and Postgraduate courses in Special Education are offered at Kenyatta, Moi, Maseno and Methodist universities. The training in these universities involves equipping teacher trainees in various SNE areas such as that of the VI learners at the University of Nairobi (TSB 2/2000).

\section{Conclusion}

Teacher education for teachers of the VI has been one of the challenges towards achieving quality education for VI learners in Kenya. While education for the VI was established in the year 1946 through the establishment of Thika Institute for the Blind, there was a shortage of trained personnel to handle the VI learners. The teaching force comprised of a few experienced European tutors who offered on-the-job training to the untrained teachers in the institution. While there were some developments in the year 1986 through the establishment of KISE that has played a key role in providing additional SNE training to qualified teachers, the institution remains the only college besides a few universities that directly prepares teachers to handle the VI. This research therefore concludes that whereas some efforts have been undertaken to develop teacher training programs for teachers of the VI in Kenya, the available programs are insufficient to provide the required teaching force. There is need therefore for much to be done towards this course in order to enhance quality in the nature of education for the VI in Kenya.

\section{References}

Chikati, D.K., Wachira, L.N., Mwinzi, J.W. (2019). Development of Special Education for the Visually Impaired Learners in Kenya: A Historical Perspective. European Journal of Special Education Research, 4 (2), 80-92. Government of Kenya (2010). Constitution of Kenya. Nairobi: Government printer.

Munyi, C.M. (2017). Analysis of Teachers' Perceptions on Instruction of Braille Literacy in Primary Schools for Learners with Visual Impairment in Kenya. Unpublished PhD Thesis, Kenyatta University, Kenya.

National Gender and Equality Commission (2016). Access to Basic Education by Children with Disability in Kenya. Nairobi: Government printer.

Ojwando, J.O. (1990). A Study of the Historical Development of the Primary Teacher Training Programme for Teachers of the Visually Handicapped in Kenya. Unpublished M.Ed. Dissertation. Kenyatta University, Kenya.

\section{Archival Sources}

KISE/1: File of records of KISE 1987-1990

KNA, BY/12/21: Kenya National Archives (KNA)-Salvation Army Blind School, Piece

KNA, AB/14/34: Education, Blind School Thika. Piece Dates 1949-1955

TSB, P/2/1978: File of minutes of Board of Governors of Thika Primary School for the Blind 1975-1978

TSB, P/3/1997 : File of minutes of Board of Governors of Thika Primary School for the Blind 1987-1997

TSB, S/1/2000: File of records of annual graduation/speech days, 1987-2000

KNA, KTI/3/7/11: Training of Blind Africans, Correspondence Concerning Training and Education for the Blind 